\title{
Uso de la tierra y expansión urbana en las comunidades campesinas de los distritos de Andahuaylas y Anta, regiones Apurímac y Cusco, Perú
}

\author{
Felipe Rafael Valle Díaz \\ Universidad Nacional José María Arguedas \\ Ciudad Andahuaylas-Perú \\ fvalle@unajma.edu.pe \\ orcid.org/0000-0003-0855-9688 \\ Clemente Marín Castillo \\ Universidad Nacional José María Arguedas \\ Ciudad Andahuaylas-Perú \\ cmarin@unajma.edu.pe
}

\section{RESUMEN}

El objetivo principal es comprender e ilustrar las consecuencias de la expansión urbana en el estado del uso de la tierra en las comunidades campesinas de los distritos de Andahuaylas y Anta, regiones Apurímac y Cusco. El enfoque de investigación cualitativo, el diseño de investigación es micro etnográfico, el nivel de investigación ex pos facto. La población comuneros calificados en los territorios comunales campesinos donde se evidencia desde hace más de veinte años, hechos de expansión urbana. La muestra es intencional, no probabilística, se seleccionó a ex autoridades de la directiva comunal, llegando a un total de 20 y la fotografía satelital. La técnica fue la entrevista semi estructurada, sumado la captura de foto satelital por cada 5 años en el periodo 2019 a 1975. La conclusión: que el cambio de uso del suelo agrícola hacia suelo urbano, se centró en: 1) el valor que adquirió el predio rural cuando se formaliza con un título de propiedad, para los predios de dominio privado, 2) la proximidad de los territorios comunales campesinos a la ciudad, establecieron una disfunción organizacional, abriendo camino a la división y partición de predios agrícolas, 3) el papel de la autoridad representativa del poder judicial, el juez de paz, que sirvió para consolidar proceso de transferencia internos de predios rurales próximos a la zona urbana. A pesar que la ley 24656, es tácita, respecto al proceso de compra venta al interior de la comunidad campesina y la constitución política del Perú del año 1993, donde indica que la pérdida de la condición de comunidad y parcelación ocasiona el re vertimiento de tierras hacia el estado; ello no es suficiente porque las formas asociativas y condiciones de posesión en tierras eriazas comunales, por los asentamientos urbano marginales, presentan otra connotación, creando un nuevo contexto de necesidad poblacional y atención del estado. Palabras Clave: cambio de uso, expansión urbana, comunidad campesina. 


\title{
Use of the land and urban expansion in the campesin communities of the districts of Andahuaylas and Anta, Apurímac and Cusco regions, Peru
}

\begin{abstract}
ABSTRAC:
The main objective is to understand and illustrate the consequences of urban expansion on the state of land use in the peasant rural communities of the districts of Andahuaylas and Anta, Apurímac and Cusco regions. The qualitative research approach, the research design is micro ethnographic, the level of research ex post facto. The population qualified comuneros in the communal peasant territories where it is evident for more than twenty years, facts of urban expansion. The sample is intentional, not probabilistic, ex-authorities of the communal directive were selected, reaching a total of 20 and satellite photography. The technique was the semi-structured interview, adding the satellite photo capture for every 5 years in the period 2019 to 1975 . The conclusion: that the change of use of agricultural land towards urban land, focused on: 1) the value it acquired the rural property when it is formalized with a property title, for the properties of private domain, 2) the proximity of the peasant communal territories to the city, established an organizational dysfunction, opening the way to the division and partition of agricultural properties, 3 ) the role of the representative authority of the judiciary, the justice of the peace, which served to consolidate the internal transfer process of rural properties close to the urban area. Despite the fact that Law 24656 is tacit, with respect to the purchasesale process within the peasant community and the political constitution of Peru in 1993, where it indicates that the loss of community status and subdivision causes land revert. towards the state; This is not enough because the associative forms and conditions of possession in communal wasteland, by the marginal urban settlements, present another connotation, creating a new context of population need and state attention.
\end{abstract}

Key words: change of use, urban expansion, rural community

Artículo recibido: 19. agosto. 2020

Aceptado para publicación: 12. setiembre. 2020

Correspondencia: edjm_25@hotmail.com

Conflictos de Interés: Ninguna que declarar 


\section{INTRODUCCIÓN}

La ley 17716, El Peruano (1969) conocida como ley de Reforma Agraria Peruana, fue promulgada el 24 de junio de 1969, en el periodo de gobierno del general Juan Velazco Alvarado, cuyo propósito fue, redistribuir los latifundios en poder de terratenientes. Para el año 1969 según datos estadísticos del Instituto Nacional de Estadística e Informática del Perú (INEI), estos terratenientes comprendían el 1\% de la población y en ellos estaba concentrada la propiedad de la tierra, además de los factores productivos que solo era accesibles para la producción y sostén de la clase terrateniente. Cuando se promulgó la ley de Reforma Agraria, se desarrolló un proceso de afectación, expropiación, justiprecio. Las dos primeras etapas fueron concluidas parcialmente, obteniendo resultados superiores a un promedio aceptable; sin embargo, la tercera etapa, sufrió revés y retraso, porque a la fecha existe una deuda agraria producto de incumplimiento de cancelación de la deuda hacia los descendientes de terratenientes o tenedores de bonos de deuda agraria, cuyos valores activos, están en proceso de sentencia judicial e indemnización de daños y perjuicios, esto representa una alerta, porque el fallo judicial internacional se logró el año 2016, debido a que estaban inmersos pensionistas norteamericanos, específicamente ubicados en la Florida, quienes de buena fé, adquirieron estos bonos de deuda agraria; el estado peruano asumiría una deuda por más de 1300 millones dólares americanos, según opinión, fallo inicial del Tribunal Constitucional Peruano, realizado el año 2018, donde la deuda debe cancelarse en dólares americanos, más el mecanismo que aprobaría el Ministerio de Economía y Finanzas del Perú, respecto a los intereses. Las dos primeras etapas, fueron parcialmente concluidas, en algunas regiones del Perú, la expropiación directa fue hecha, por lo yanaconas o herbajeros, adelantándose al proceso de afectación, iniciando la toma de tierras antes de la publicación, notificación, trabajos preliminares de los fiscales y equipo técnico. Por ello, el proceso de afectación y expropiación de la tierra tuvo un retraso en la región Apurímac. Hasta el año 1987, las comunidades campesinas formadas desde la Reforma Agraria y otras reconocidas por el proceso de Reforma Agraria, no tenían saneado por completo la propiedad de la tierra, ello generó conflictos de linderos con colindantes, apropiación de tierras colindantes, usurpación y posesión de tierras, debilidad en la organización por la falta de personería jurídica. Estos hechos trajeron como consecuencia vulneración, atropello de los derechos de las comunidades campesinas, grupos campesinos organizados, estableciendo como medida preventiva áreas territoriales en litigio, que a la fecha son difíciles de solucionar e inclusive se encuentran en abandono. El proceso de expropiación fue directo, al amparo de mecanismos que permitieron la comunicación, reclamos, levantamiento de reclamos, ingreso y toma de tierra, concluyendo con el acta de entrega y posesión campesina de la hacienda agraria.

Sobre las comunidades de la provincia de Anta, obran en el poder judicial y el archivo departamental del Cusco, documentos que dan cuenta de los litigios por terrenos que pertenecieron a los terratenientes y hacendados de la época, donde en un afán de apoderarse o hacer respetar derechos ganados por haber sido serviles de los desposeídos por la reforma agraria; los hombre y mujeres que labraban la tierra, perdieron la vida en sendos enfrentamientos a punta de palos, piedras y herramientas de uso doméstico, que quedo gravada en la memoria de muchos jóvenes de la época que ahora son parte de la clase dirigencial de estas comunidades campesinas. A lo cual también se suma los maltratos familiares, violaciones sexuales, abandono familiar y otros hechos que 
ocurrieron en esta época. Al igual sucedió en la provincia de Andahuaylas, obran en el archivo del poder judicial, despacho de tierras, las demandas surgidas durante el proceso de formalización del territorio comunal, que fueron absueltas, bajo fallo judicial a favor de la comunidad campesina.

Es precisamente en la génesis de la formación de estos entes comunales, algunos integrantes que tenían cierto nivel de instrucción y poseían dinero, afrontaron económicamente los gastos que demandaron sostener en las luchas clasistas a cambio de mantenerlo en prenda por en espacio de tiempo, extensos terrenos que se encontraban en su posesión. Que pasado el tiempo se apoderaron de los mismos y hoy mantienen otra vez litigios entre miembros en razón a que existen terrenos inscritos en los registros públicos que pertenecieron a la comunidad.

Las comunidades campesinas están reguladas por la ley 24656 y 24657 . La primera y segunda ley fue aprobada, promulgadas y publicadas en el diario oficial El Peruano (1987) La ley 24656, denominada Ley General de Comunidades Campesinas y Nativas, comprende la forma organizativa en que asocian los comuneros calificados para administrar un territorio, bajo posesión-explotación, acreditada por organismos institucionales inmersos en vigilar, coadyuvar la gestión al interior de las comunidades campesinas. La ley 24656, contempla la forma en que deben organizarse para distribución equitativa de la tierra, sin favorecer la acumulación de tierras, negando la enajenación de tierras debido a que se sostiene en que el principio de posesión y explotación se basa en el manejo continuo, objetivo, acreditado por la organización comunal hacia un comunero calificado o en otras consideraciones en un comunero eventual con intenciones de pertenecer-integrarse a la comunidad campesina. La forma de integrarse a la comunidad campesina, que es común, antigua, por mantenerse en el tiempo, es mediante los lazos de parentesco, los cuales refuerzan la integración para luego desarrollar el sentido de pertenencia. El sentido de pertenencia es aquel donde el comunero eventual pasa al estado de calificado, además de estar consciente, aceptar las formas de organización y trabajo de la comunidad campesina que lo acoge. Al pertenecer a la comunidad campesina, obtiene derechos directos, uno de ellos es acceder a la distribución equitativa de terrenos para la explotación y mantenimiento de la familia campesina. Es así que, a través de la asamblea general, se aprueba la distribución de parcelas pendientes de entregar para el manejo familiar, las cuales están ubicadas en diversos sectores. Estos sectores están clasificados en zonas según su potencialidad productiva.

En la actualidad la región de Apurímac, es una de las regiones que presenta mayores índices de pobreza extrema en el país, según el Instituto Nacional de Estadística e Informática -INEI (2018), supera el promedio nacional peruano de extrema pobreza en 3.6\%; enfrenta actualmente problemas preocupantes de competitividad regional, manteniéndose estable entre los intervalos intermedio e inferior durante más de nueve años consecutivos, además es reconocida por la conflictividad y dadas las estadísticas de producción nacional ofrecidas por el Ministerio de Economía y Finanzas del Perú (2020), representan a partir del año 2016 el 1\% del Producto Bruto Interno Peruano (PBI).

Uno de los problemas relevantes en los distritos de Andahuaylas y Anta, es la expansión urbana que se realiza en los límites de los territorios de la comunidad campesina, donde el marco jurídico es contradictorio, desde la posición de comunidad campesina, del plan 
urbano director por la Municipalidad y la Constitución Política del Perú. Cada una de ellas enmarca disposiciones, que al final confunden a las instituciones inmersas respecto a la función que se debe hacer. Las comunidades campesinas de Los Ángeles, José María Arguedas de Ccapaccalla, Ccapaccalla, del distrito de Andahuaylas, se viene desarrollando la expansión urbana, mediante la conversión de uso del suelo agrícola a urbano, con un avance del 60\% del territorio comunal, según Valle \& Huamán (2019) Los resultados del proceso de titulación en la zona de producción agrícola contenida en el margen izquierdo río Chumbao, comprendida entre los sectores Cuncataca, Choccepuquio, Ccoñeccpuquio, Lirios y Rumi Rumi; fue fuerte en el sentido del desplazamiento y pérdida en volúmenes de producción de cultivos temporales caso maíz amiláceo, hortalizas por la superficie de 291.32 has, en algo más de diez años, que desplazaron 293.71 toneladas de maíz amiláceo considerando como el cultivo frecuente. Además, la cantidad de área estimada no saneada antes del proceso de titulación y cambio de uso de suelo en la zona de producción agrícola margen izquierdo del río Chumbao, al 2004, fue alta en un 90\%, que comprende más de 410 has. La cantidad de área estimada total saneada por el proceso de titulación, en la zona de producción agrícola margen izquierdo del río Chumbao, fue fuerte en 291.32 has, que comprende el $79 \%$ aproximadamente del área total de estudio. Los resultados monetarios del proceso de cambio de uso de suelo a partir de la titulación en la zona de producción agrícola margen izquierdo del río Chumbao, fueron del año 2004 hacia 2017 que alcanzó la suma promedio monetaria de s/. 2 913, 200000 millones de soles.

Para el distrito de Anta, las comunidades campesinas de San Cristóbal de LLuscanay, en la margen derecha de Hatun Mayu y Anansaya-Urinsaya-Qollana en la margen izquierda, ambos dentro de la capital de la provincia de Anta. Donde como otras comunidades aledañas, sus miembros en su mayoría son profesionales y se convirtieron en empleados públicos, abandonaron las habituales actividades del cultivo de la tierra y el pastoreo del ganado a consecuencia de la expansión urbana que genera la irreparable pérdida de áreas de pastoreo y cultivo, sumado a la desaparición de los canales de riego y casi extinción del agua utilizado para el riego. La ley de comunidades campesinas prohíbe que los servidores públicos o profesionales sean miembros de las comunidades campesinas en el Perú. Dado este contexto, están en la misma condición, la expansión urbana inició de forma lenta a partir de los años 1990, para impulsarse en forma fuerte, llegando hasta conversiones de predios y lotización, a partir de los años 2000 en adelante. Asimismo, el otro problema, para ambos casos de estudio es que las hectáreas de suelo de producción agrícola son sustituidas por el concreto, que modifica la dinámica del paisaje, la producción es reemplazada en cantidad considerable por mayor comercio interregional, es decir traemos productos de otra región. Además de ello, la servidumbre de riego, la cual tiene una función de seguridad y evacuación frente a crecidas de río, evitando embalsamientos en barrios o sectores urbanos ubicados cerca del río, desaparecieron, inclusive habiendo usurpado terreno de cauce de quebrada para lotización urbana.

Por esta razón y las circunstancias expuestas, es que la investigación tiene por finalidad llegar a conocer el avance del proceso de expansión urbana, y la situación que atraviesa y en que quedan el suelo agrícola y territorio campesino; a partir de los hechos dados en su entorno activo. El problema general fue: ¿Cuáles son las consecuencias de la expansión urbana en el estado del uso de la tierra en las comunidades campesinas de los distritos de Andahuaylas y Anta, regiones Apurímac y Cusco, Perú? El objetivo general fue: 
Comprender e ilustrar las consecuencias de la expansión urbana en el estado del uso de la tierra en las comunidades campesinas de los distritos de Andahuaylas y Anta, regiones Apurímac y Cusco.

\section{METODOLOGÍA}

Según Arial, Carrasco, Bernal y Hernández et al. (2010, 2005, 2012, 2014) La investigación se ubica en el enfoque cualitativo, tipo de estudio y diseño micro etnográfico. El nivel de la investigación ex pos facto, porque buscamos conocer los hechos después que han ocurrido, no se modifican o alteran, buscamos las causas para explicar los hechos actuales. La población comuneros calificados en los territorios comunales campesinos de: Los Ángeles, José María Arguedas de Ccapaccalla del distrito de Andahuaylas y San Cristóbal de Lluscanay, en la margen derecha de Hatun Mayu y Anansaya-Urinsaya-Qollana del distrito de Anta, pues en estos territorios comunales campesinos desde hace más de veinte años se estuvieron realizando hechos de expansión urbana, sumado a la fotografía satelital de los ámbitos geográficos que contienen las expansiones urbanas desde los años 2019 a 1990. La muestra es intencional, no probabilística, se seleccionó a ex autoridades de la directiva comunal, llegando a un total de 20 y las capturas fotográficas son cada 5 años en forma retrospectiva. La técnica fue la entrevista y captura de fotografía satelital del ámbito geográfico que contiene los distritos de Andahuaylas y Anta. El instrumento un cuestionario semi estructurado, con 10 preguntas y 07 capturas fotográficas de los años: 2019, 2014, 2010, 2005, 1969.

\section{MARCO TEÓRICO.}

Según lo dispuesto en el Ministerio de Agricultura y Riego del Perú (2018) un área o sector agrícola es un espacio físico, que proporciona condiciones para la producción y explotación agropecuaria. Hacemos referencia que la producción agrícola parte de la actividad agrícola que se realiza en un área o sector. Para esta misma institución, específicamente en la Dirección de Comunidades Campesinas y Nativas, el territorio; es el área espacial cuyos recursos son controlados por personas o instituciones, para desarrollar y mantenerse en un sistema socio ecológico.

Para Rosina Valverde (1998) "un resultado de impacto, es un cambio social permanente en la condición de las personas con quienes trabajamos o en la del medio ambiente en el que actuamos (suelos, agua, bosques, animales, flores, plantas, ríos etc.). Es un cambio en las condiciones de acceso y de control en las personas o grupos de personas, y en las condiciones del medio ambiente, que aumenta o disminuye sus posibilidades de subsistir y de reproducirse...".

Según Juan Pérez (2013) El espacio geográfico es trascendental para el estudio de las asociaciones entre las actividades económicas, formas de subsistencia humana y condiciones ambientales, siendo la unidad de análisis para el estudio de las interacciones entre el territorio, las condiciones naturales y socioculturales. En 25 años desaparecieron bosques, impactando negativamente, sumado al desplazamiento de la población campesina hacia las ciudades, abandonando e escenario agrícola, cuya producción minimizada, deteriora preservar la identidad de las formas de siembra del maíz, siendo sustituida la agricultura familiar a pequeña por un tipo de agricultura en extensiones 
mayor, deteriorando el suelo por la práctica ceñida a lo comercial. La expansión de azolvamiento y la eutrofización de los cuerpos de agua, son evidencias del riesgo la calidad del consumo de agua, generado por la indebida disposición de residuos sólidos en ambientes naturales. Otro factor importante es la quema de bosques, al ser no controlados devastan zonas considerables, y a la vez se convierte con mayor vulneración la propagación y asentamiento de plagas por mayor periodo de tiempo. El crecimiento poblacional es la otra variable que está afectando los recursos, suelo, agua, forestal. La cercanía del poblado, hace que se induzca a convertirlo en una urbe para barrios residenciales.

Para Bocco (2007) el objeto de estudio está enfocado en el análisis de hechos y fenómenos, respecto a las condiciones en las que se encuentran los componentes del ambiente: aire, suelo, agua y biota. El análisis de los factores que están ocasionando el cambio de uso del suelo en el espacio geográfico que comprende los territorios comunales campesinos próximos a la zona urbana, tiene sustento en la disciplina geográfica, ya que se analiza la interacción entre las categorías, en asociación con los componentes del ambiente y su interacción con la sociedad y sus actividades, siendo estas el deterioro y abandono de la tierra de cultivo, altos costos de insumos, el crecimiento poblacional y de los asentamientos urbanos, además de las institucionalidad campesina.

Además, Clout (1976) nos precisa que la geografía rural tiene elementos teóricos que permiten contextualizar en el tiempo y espacio, los avances relacionados con investigaciones que tienen como objeto de estudio los ambientes rurales. El espacio geográfico rural es primordial, ya que en éste se producen los bienes y servicios para las familias que viven en el campo y en la ciudad. También en éste ocurren cambios y procesos asociados con los grupos humanos y sus actividades, como el cambio de uso del suelo.

Para Hernández et. Al (2017) Se hace extremadamente imperioso, evaluar las transformaciones que ocurren en las propiedades edafológicas, por el cambio de uso de los suelos, en los diferentes ecosistemas; para de esta forma tomar las medidas adecuadas para su mejoramiento y conservación. A nivel de microcuenca este estudio es pertinente para un relieve alomado, pre montañoso, en la cual predominan bosques primarios y secundarios con especies arbustivas, pastizales y cultivos como el maíz, papa, entre otros en su parte baja, media y alta. En la investigación se presentan los resultados sobre cambios en sus características morfológicas que son apremiantes, además que sustentan la pérdida de biodiversidad y soporte del ecosistema, ello producto de la actividad antropogénica, como: sobrepastoreo que degrada el suelo, prácticas de manejo de cultivo inorgánicas, esto genera como consecuencia el abandono de las tierras, hacia otras o ciudad para buscar mejorar los ingresos. La producción semi industrializada del cacao, trajo consecuencias serias en el manejo del suelo y cultivo, en respuesta a la demanda comercial.

Según Velásquez \& Bocco \& Siebe (2014) El de suelo es una expresión cultural de las prácticas de apropiación del territorio, cuya escala de análisis es a nivel de parcelas, que contienen patrones que nacen de acciones consensuadas por los actores sociales, el cambio de uso del suelo, es la forma permanente práctica de apropiación del territorio, 
además existen diversos conceptos asociados a ciencias naturales con una fuerte disociación del elemento central, el hombre.

Conocer que el suelo es la porción de superficie terrestre, la cual es aprovechada para las actividades económicas. El suelo tiene varios usos: agrícola, pecuario, vivienda, esparcimiento, industria, entre otros, según Valle y Huamán (2019) la decisión de ¿para qué usarlo? depende de la disponibilidad de recursos que permitan crecer y aprovechar el suelo, que está ligado al capital de inversión, a la forma de gestión y tecnología a aplicar modificando el medio ambiente. El suelo destinado a la agricultura, adquiere un valor representativo en el tiempo a partir de un aprovechamiento racional que generalmente es a mediano plazo, y los retornos de la inversión son considerables, no extremos; si se realiza en suelos de superficie grandes conocidos como fundo o hacienda. La agricultura basada en el aprovechamiento racional de superficies pequeñas conocidas como minifundio, sus retornos de inversión muchas veces son ínfimos o negativos. El cambio de uso de suelo, son acciones, actividades de las personas o grupos que realizan sobre un determinado tipo de superficie, revirtiendo la primera forma de explotación hacia una nueva, esta decisión es tomada porque el cambio de uso del suelo le reportará un mayor costo de oportunidad y beneficios. El cambio de uso se sostiene según las normas establecidas. Para el caso de estudio están inmersas en la normatividad y plan regulador del crecimiento urbano de la Municipalidad Provincial.

Además, Valle y Huamán (2019) donde citan a Hernando De Soto (1998) para fortalecer, sostener que un mercado de tierras, es un sistema en el cual el recurso "tierra" se encuentra económicamente regulado por el mercado, es decir, por la oferta y la demanda. Sin embargo, el desarrollo de este mercado no se produce por sí solo, hay una serie de elementos que van a facilitar o trabar su desarrollo. Sin embargo, Valle y Huamán (2019) indican que, en el Perú, el mercado de la tierra tiene las siguientes características: a) Tendencia al minifundio, extensión de parcelas menor a 10 has. b) Mercado de transferencias incipiente, las unidades agropecuarias han sido adquiridas por sus dueños a partir de contratos de compra-venta con terceros, lo que significa que estamos ante un mercado de tierras en estado incipiente, transferencias que no generan más valor y que, según se sabe, muchas veces no llegan a formalizarse legalmente. c) Falta de titulación, no existe un mercado de tierras que funcione, si no se cuenta con propiedades saneada. Es decir, la acreditación del derecho del propietario garantizará tanto la explotación del bien por parte del propietario y dará seguridad a las personas que adquieran dicho derecho en el futuro.

Asimismo, Romero (2016) en la ciudad de Lima-Perú, los territorios de las comunidades campesinas se concentran al sur y este, entre los distritos de Comas, Carabayllo e Independencia. Son las ubicaciones de territorios comunales, más próximas a la capital Lima. Sin embargo, en algunas de ellas, se permitió tomar parte del territorio para ampliación de carreteras primarias y secundarias, caso comunidad de Jicamarca en el distrito de San Juan de Lurigancho. Este proceso sucede por el motivo de la legislación vigente, donde se aprueba competencias para los gobiernos locales y el Ministerio de Vivienda, para que puedan incorporar la libre disponibilidad de terrenos que consideren necesarios para la expansión urbana. Esto sucede generalmente por la formación de dirigencias paralelas, ajenos a la comunidad, que invaden y luego buscan contacto para legitimar su posesión, la cual se fortalece cuando se ejecuta una obra pública, siempre y 
cuando el terreno sea de libre disponibilidad. En la comunidad se invade una Proción de territorio, se asientan, dando la figura de asentamiento humano, e inician el proceso de legitimar su posición, mediante la fuerza para no ser desalojados, ante reivindicación de la comunidad u otros; fuerzan la negociación con la comunidad, procede su inscripción mediante la figura administrativa de abandono de la tierra, es decir la posesión y explotación de aquella porción de terreno. Es más, existe problemas judiciales de dirigencia, por ello no se puede negociar una venta de porción de terreno, por lo cual queda abierto el proceso de abandono.

Cuadros (2019) la comunidad campesina de Orcotuna, ubicada en al valle del Mantaro, proviene de un origen colonial, reconocida la organización comunal y titularidad del territorio comunal. No nace con la reforma agraria, por ello los cambios en la tenencia de la tierra y el uso de la misma son influenciados por los procesos administrativos de titulación de tierras ejecutados 20 años atrás, los cuales generaron tensiones. Los procesos de titulación de tierras, mediante la modalidad administrativa contribuyó a que áreas eriazas o en supuesto abandono al interior del territorio comunal fueran posesionadas, iniciando un proceso de expansión urbana, mediante las constancias de posesión u otros documentos que avalan la posesión o conducción del terreno o predio. Asimismo, por el motivo de la expansión de infraestructura social pública, luz eléctrica, agua potable, desagüe; permitió que la porción de territorio sea considerada como expansión urbana, por el municipio local, con el visto bueno del Ministerio de Vivienda, ello ocasionó que se desmembrara una considerable cantidad de territorio, además se impulsó tensiones entre los antiguos y nuevos comuneros, por motivo que los últimos eran ocasionales y solo buscaban un lote de terreno para vivienda. Asimismo, se inició controversias por el establecimiento de los hitos, frente a las porciones de territorios desmembrados, que la comunidad campesina no reconocía, a todo ello se suma que muchos procesos de demandas judiciales para recuperar áreas de territorio comunal fueron paralizados o perdidos por el motivo que la junta directiva comunal no estaba registrada adecuadamente. Termina el análisis, precisando que los grupos familiares al interior de la comunidad campesina, presionaron a la directiva, brindaron información a terceros para consolidar la posesión y asentamientos humanos futuros, lo cual garantiza la preponderancia del poder del grupo familiar ante el poder comunal, en otras palabras, las necesidades familiares superaron a los objetivos de la comunidad y de la mayoría de comuneros. Ante ello, la consolidación de asentamientos humanos, por conversión ficticia inicial hacia una asociación de productores, fortaleció el tránsito y cambio del uso de la tierra, desde agrícola hacia la urbana.

Valle y Cruz y Yauris (2020) la investigación concluyó que “A mayor generación de riqueza a partir de una adecuada organización comunal al interior del territorio comunal, mayor será la acumulación de capital en la ciudad". Es decir que el contexto de la comunidad campesina dada su organización o directiva, territorio saneado, programación de faenas, obligatoriedad de registros o documentos, entre otros; permiten sostener condiciones para generar riqueza al interior de la comunidad, es decir poseer más bienes, de tal forma que, por decisión de la familia, puedan ser asignados en la ciudad, a través de la adquisición de bienes inmuebles, los cuales garanticen un capital posterior que pueda ser usado como apalancamiento financiero, coadyuvando a mejorar sus condiciones de la vivienda ubicada en la ciudad. 


\section{RESULTADOS}

Para el caso del distrito de Andahuaylas, en los sectores de Cuncataca, Los Ángeles, Choqepuquio, Ccapaccalla, Jose María; todos ellos producto de la desintegración de comunidades campesinas como: Los Ángeles, Ccapaccalla, José María Arguedas y de parcialidades o pequeñas propiedades rurales caso Cuncataca, podemos confirmar que existe desintegración de la organziación comunal campesina. Además, en el ambiente rural (campo) están ocurriendo cambios significativos e impactos que provocan problemas ambientales y socioculturales a nivel local, regional, por ejemplo, usos del suelo no acordes con su potencial y capacidad. En la actualidad, los ambientes rurales están desapareciendo, o bien, se pueden observar intercalados en espacios semi urbanos o urbanos, resultado de la interacción de diversos factores económicos, demográficos, socioculturales, políticos $\mathrm{y}$, en ocasiones, físico - geográficos. No obstante, la disminución y deterioro de estos espacios, no sólo es una problemática que deben atender las autoridades y especialistas en análisis espacial, también, está el problema de expansión urbana o el incremento de las fronteras agrícolas en ambientes forestales (cambio de uso del suelo), que al final terminan favoreciendo la expansión urbana.

Una función del Proyecto Especial de Titulación de Tierras y Catastro Rural, años 90 del siglo XX e inicios primera década del siglo XXI, fue el saneamiento físico-legal de predios rurales, que es un mecanismo de información, registro, protección del predio rural, además brinda información única, probada sobre la ubicación y características de las tierras que constituyen un elemento importantísimo en la generación de un mercado de tierras, esta información relevante se centra en la ubicación cartográfica en unidades de medida métricas y protocolos internacionales, sistema de pruebas que evidencian la posesión, explotación, continuidad en el predio rural, las constancias de posesión como pruebas legales suman conformar un expediente físico que luego se registra en la propiedad inmueble, fue un proceso administrativo de adquisición de dominio de la propiedad rural, que muchos campesinos tomaron decisión en acceder, porque era difícil acceder sanear una propiedad, al amparo de los Decretos Legislativos 667 y otros, la primera década del siglo XXI, la formalización de la propiedad rural cercana a las urbes, expansión el crecimiento de los cinturones urbanos marginales, además la propiedad agrícola formal, alcanzó precios considerables por su proximidad a la zona urbana. Asimismo, el proceso de titulación y las reglas para legalizar las transferencias, no incluyen mecanismos que generen costos de transacción muy altos, porque de lo contrario haría difícil, lento que grandes sectores de propietarios, no accedan al proceso de titulación y que muchas transferencias se realicen de manera informal. La existencia de un mercado de tierras que funcione adecuadamente sería un elemento generador de desarrollo económico y, por tanto, derivaría en un aumento del bienestar general de la sociedad. En efecto, la libre transferibilidad de las tierras tiene un efecto fundamental en la asignación eficiente de este importante recurso, dado que permite que estas sean transferidas a favor de las personas que mejor uso les puedan dar, asimismo el retorno de renta o beneficio de venta, mejora gracias a la formalidad de la propiedad rural y expansión urbana. Es considerable que a partir del año 2002 en adelante el precio por metro cuadrado en los sectores de estudio halla ascendido de s/. 300 soles, por una tarea, equivalente a 1250 metros cuadrados, hacia s/. 900 soles metros cuadrado. Así, 
sucesivamente la propiedad inmueble ha tomado valor en el tiempo, hoy podemos confirmar que el metro cuadrado, oscila entre los s/. 1,500 soles a s/. 2,500 soles.

Algo más relevante es que, las comunidades campesinas, producto de la dinámica social, económica, proximidad a la ciudad, ha generado nuevas formas de relaciones y asociatividad, conformando un capital social, sólido, sostenido en su diversidad de participantes, apertura asociativa de vivienda, aspiraciones sociales de mejora en el barrio, entre otros, lo que ha direccionado hacia una nueva conformación y papel de la directiva comunal; ya no se sujetan solo a la directiva de la comunidad, queda relegada a segundo plano, porque se desactiva, y solo activan para confirmar apoyos gubernamentales respecto a proyectos productivos o asistencia social. La oportunidad de generar y establecer un asentamiento humano o sector en expansión urbana, se debió a que se fortaleció un mecanismo de invasión y acuerdo en las tierras supuestamente abandonadas en el territorio de la comunidad campesina, que luego de procesos de negociación, aval municipal se concreta la habilitación urbana por el cambio de uso del suelo, existieron la conformación de figuras ficticias, es decir creación de empresa o granja con el mínimo de implementación, solo para conseguir el pase para funcionamiento, que sería fachada para posterior conversión del uso del suelo agrícola.

El minifundio se extendió en los territorios campesinos, próximos a la ciudad, existe una atomización de predios, producto del reparto del padre hacia los hijos. La asamblea comunal, aprueba la entrega y partición de predios de posesión del padre comunero hacia sus hijos, porque no genera malestar, inequidad de tierra, por el contrario, fortalece vínculos, la futura negociación de suelos, además a partir de la partición, los hijos se establecen edificando sus viviendas. Por ello, la atomización de la atomización en zonas perimetrales del territorio comunal hacia la zona urbana, consolidó la conversión del suelo agrícola a urbano, además que la institucionalidad municipal concretó el avance de la conversión de uso del suelo, nos referimos a la creación y funcionamiento de los Centros Poblados Menores (CPM). Los CPM, son extensiones del municipio local, debido a la extenso del territorio de jurisdicción municipal y la dispersión de anexos o caseríos hacia la ciudad distrital o provincial, derivando ciertas competencias para que el funcionamiento del caserío o anexo, coadyuve a la gestión municipal, además de minimizar costos de transacción a los ciudadanos.

Para iniciar, prosiga el proceso de conversión de uso de suelo, pérdida de la dinámica del paisaje natural y cultural, descuido de servidumbre de riego y evacuación, en la comunidad campesina, suceden hechos específicos, que toman proceso: primero se abandona la conformación de nuevas autoridades, no se llega a concretar la elección de nuevas autoridades e inclusive dejan de registrar a la directiva comunal; lo cual tare consigo problemas de representación legal ante cualquier demanda. Segundo, viran la forma de administrar el territorio comunal, hacia asociaciones o comités participativos, cuyo tiempo de duración depende de la naturaleza del proyecto, es decir la directiva se adapta a las condiciones que se manifiesta, aplican, desarrollan con cada proyecto. Inclusive, permiten que las asociaciones o comités participativos, sean formados, administrados por círculo familiar. Asimismo, existe otra figura política que es el Alcalde de Centro Poblado Menor, quién asume funciones, las cuales, en muchas ocasiones, trasgreden la autonomía y función de la directiva de la comunidad campesina, por ello es notorio que poco a poco desaparece las directivas de la comunidad campesina, 
fortaleciendo la figura del alcalde del centro poblado menor. Por ello, podemos llegar a un primer resultado, que es frecuente: "Cuanto mayor sea la partición de predios aprobados por asamblea comunal, mayor será el cambio de uso del suelo agrícola por urbano" y "Cuánto mayor sea la disfunción organizativa de la directiva comunal mayor es la pérdida de la cohesión, organización campesina, por otra orientada al mercado". A continuación, mostramos tomas de captura satelital de ambas comunidades campesinas, ubicadas en las provincias de Andahuaylas de la región Apurímac y Anta de la región Cusco, que demuestran a través del tiempo, como se ha ido modificando el territorio comunal, las zonas agrícolas y el avance de la zona urbana, las tomas son desde el año 1969 al 2019.

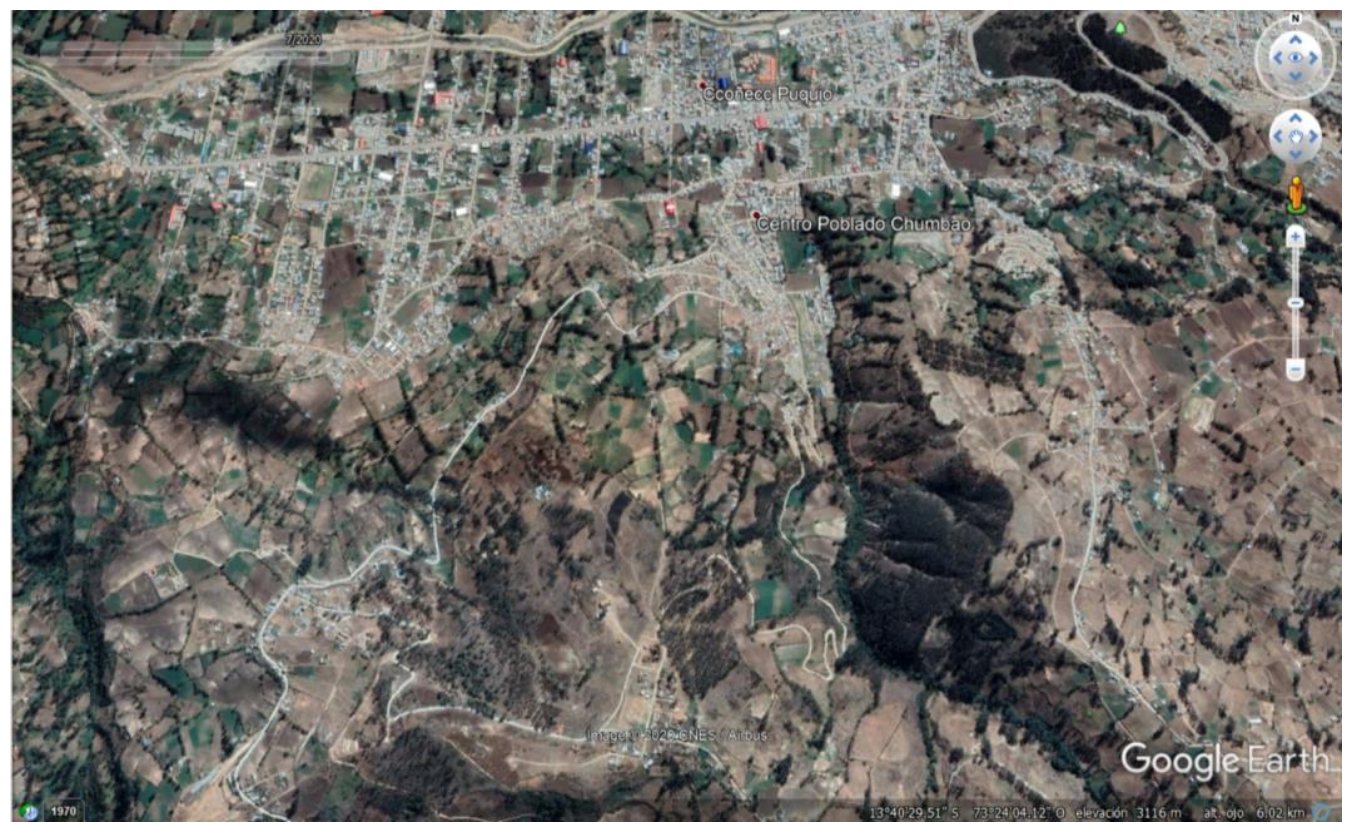

Captura fotográfica. Provincia Andahuaylas, región Apurímac. Ex territorios comunales Cuncataca. Los Ángeles y José María Arguedas Imagen 10.06.2019. Fuente: Apple TM + Google TM. 2019. Image 2020 / Airbus.

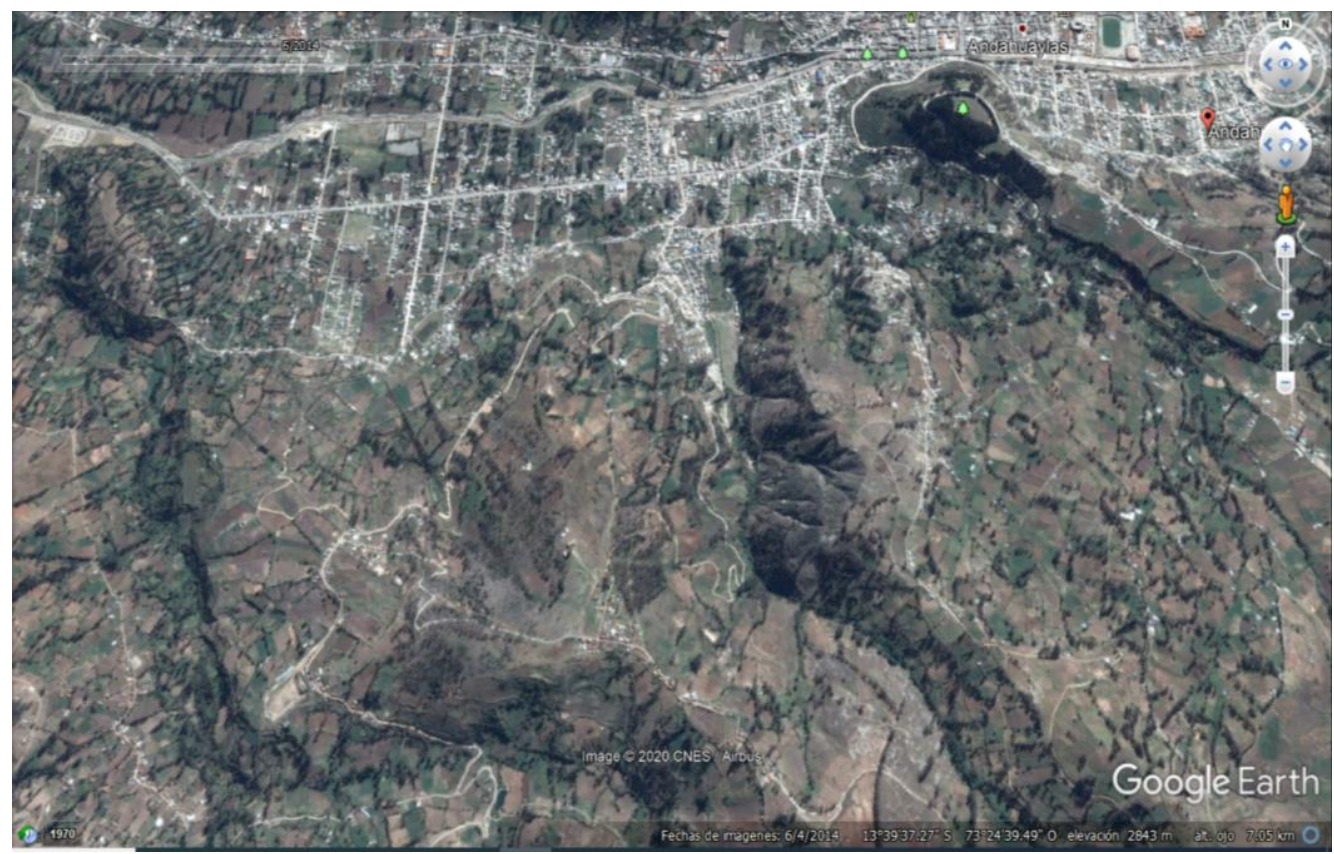

Ciencia Latina Revista Científica Multidisciplinar, Ciudad de México, México.

ISSN 2707-2207 / ISSN 2707-2215 (en línea), julio-diciembre, 2020, Volumen 4, Número 2. https://doi.org/10.37811/cl rcm.v4i2.90 p. 442 
Captura fotográfica. Provincia Andahuaylas, región Apurímac. Ex territorios comunales Cuncataca. Los Ángeles y José María Arguedas Imagen 06.04.2014. Fuente: Apple TM + Google TM. 2019. Image 2020 / Airbus.

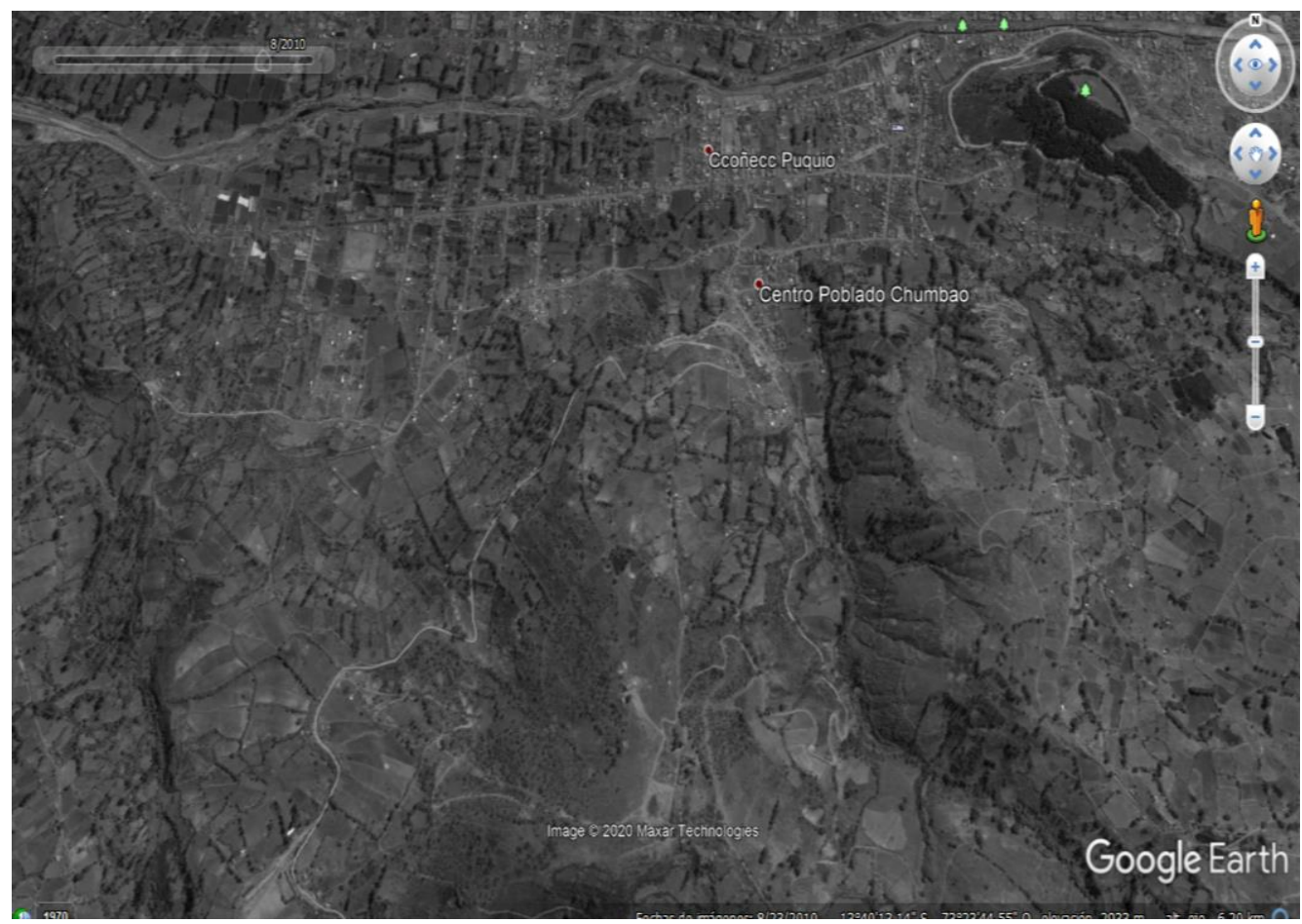

Captura fotográfica. Provincia Andahuaylas, región Apurímac. Ex territorios comunales Cuncataca. Los Ángeles y José María Arguedas Imagen 23.08.2010. Fuente: Apple TM + Google TM. 2020. Image 2010 / Maxar Techonologies.

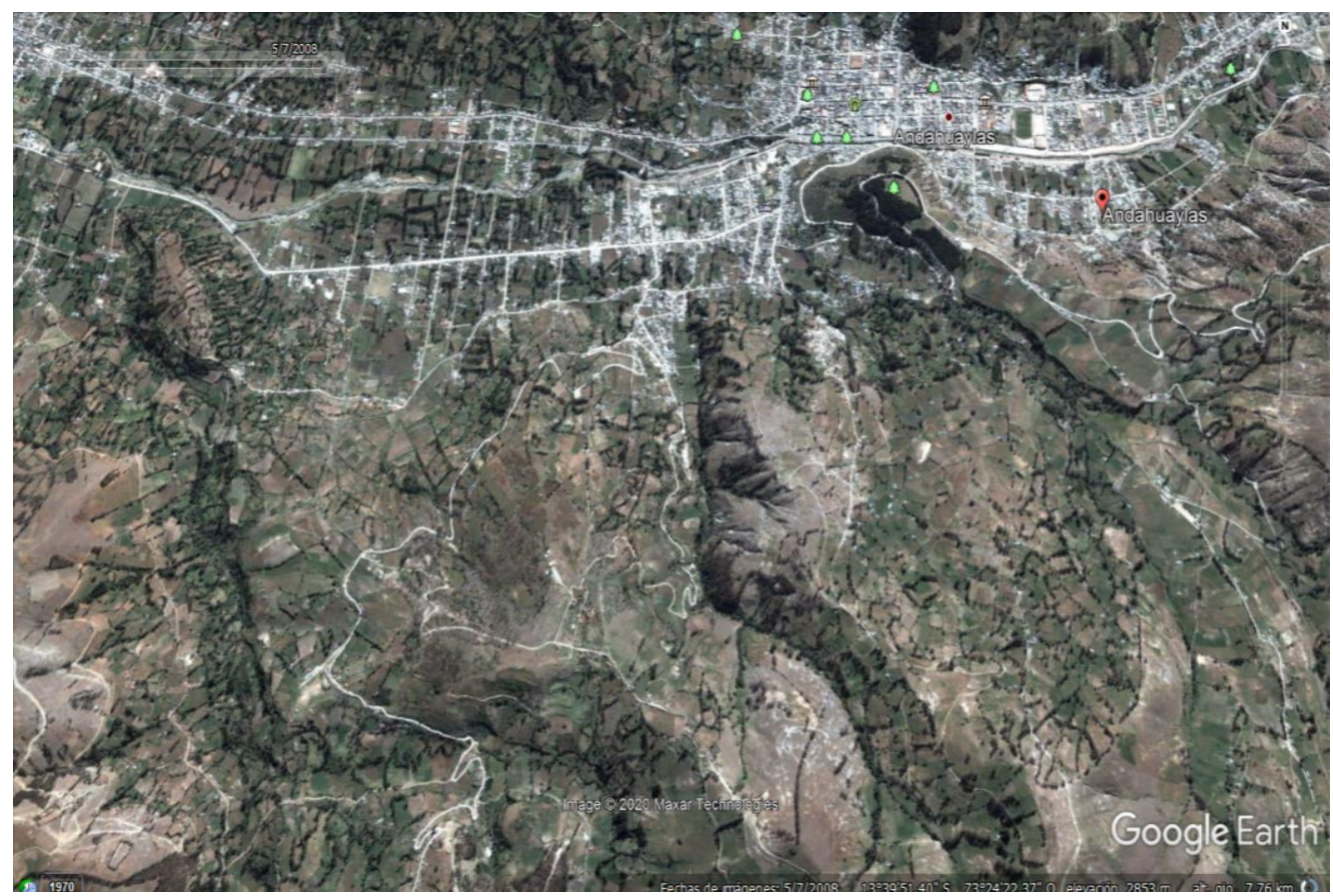

Captura fotográfica. Provincia Andahuyalas, región Apurímac. Territorios comunales Cuncataca. Los Ángeles y José María Arguedas Imagen 05.07.2008. Fuente: Apple TM + Google TM. 2020. Image 2020/Maxar Techonologies.

Ciencia Latina Revista Científica Multidisciplinar, Ciudad de México, México. ISSN 2707-2207 / ISSN 2707-2215 (en línea), julio-diciembre, 2020, Volumen 4, Número 2. https://doi.org/10.37811/cl rcm.v4i2.90 p. 443 


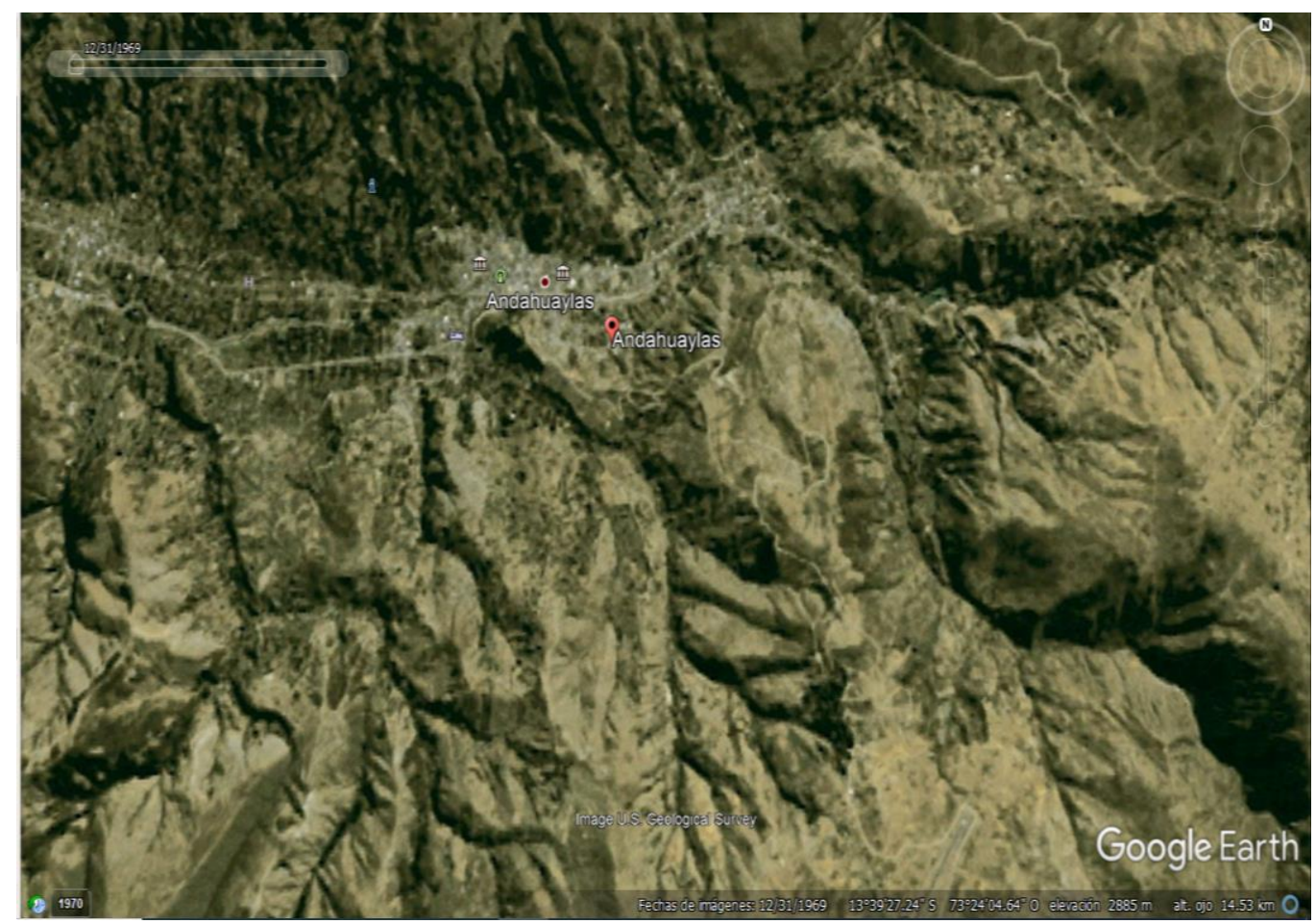

Captura fotográfica. Provincia Andahuaylas, región Apurímac. Territorios comunales Cuncataca. Los Ángeles, Ccapaccalla y José María Arguedas Imagen 31.12.1969. Fuente: Apple TM + Google TM. Image US / Geologycal Survey.

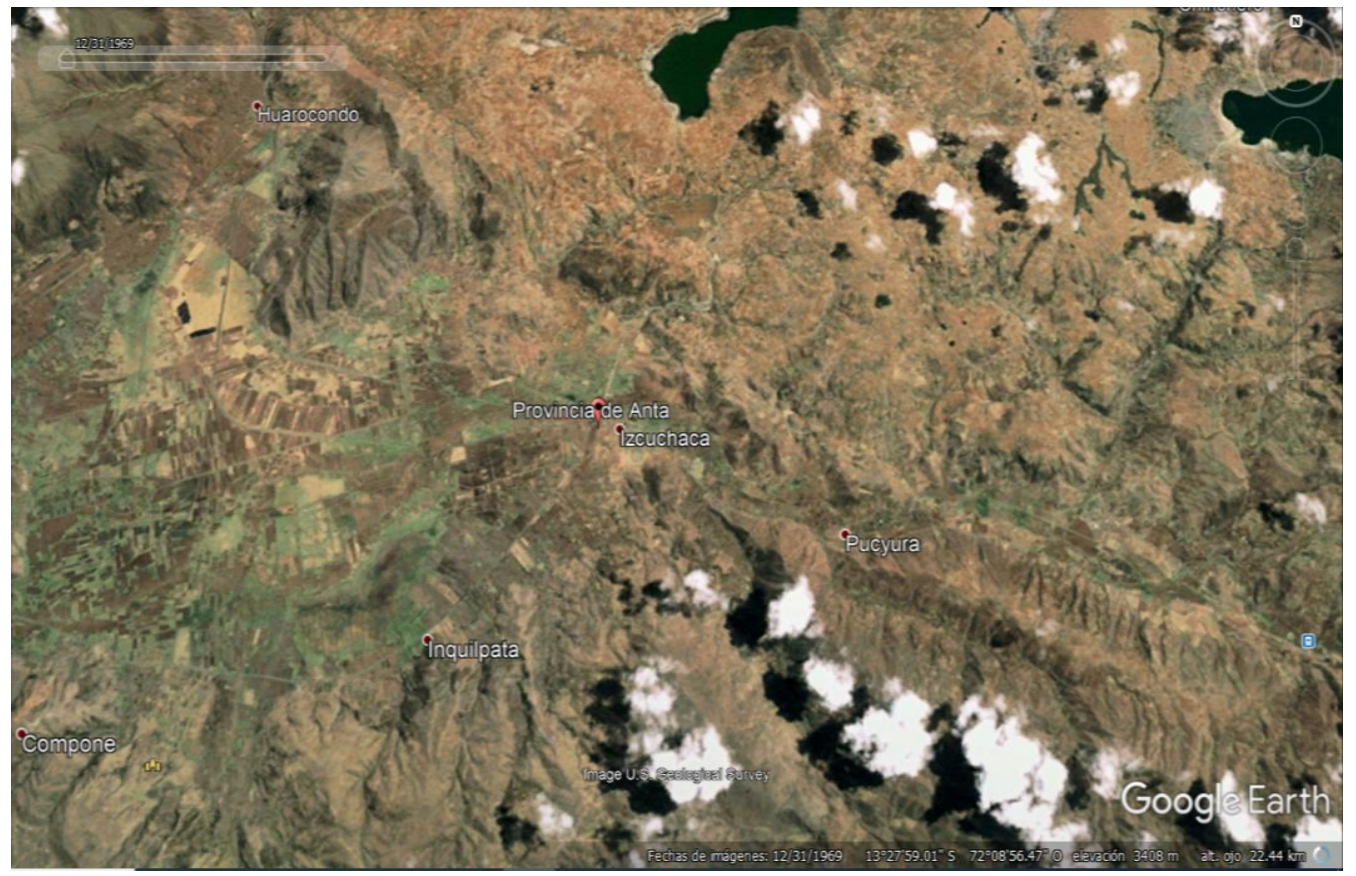

Captura fotográfica. Provincia de Anta, región Cusco. Territorios comunales San Cristobal de Llucanay y otras Imagen 31.12.1969. Fuente: Apple TM + Google TM. Image US / Geologycal Survey.

Ciencia Latina Revista Científica Multidisciplinar, Ciudad de México, México.

ISSN 2707-2207 / ISSN 2707-2215 (en línea), julio-diciembre, 2020, Volumen 4, Número 2.

https://doi.org/10.37811/cl rcm.v4i2.90 p. 444 


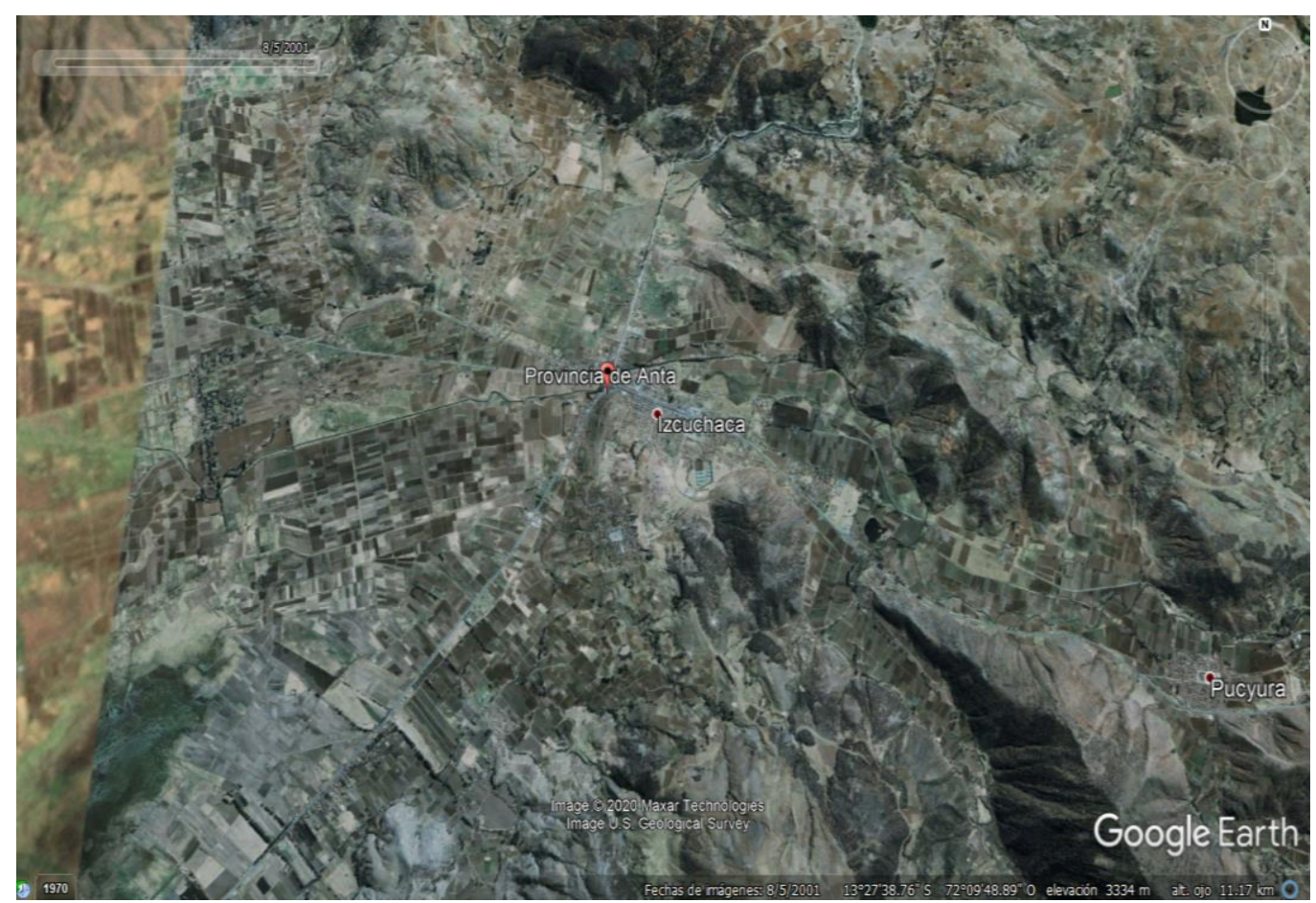

Captura fotográfica. Provincia de Anta, región Cusco. Territorios comunales San Cristobal de Llucanay y otras. Imagen 08.05.2006. Fuente: Apple TM + Google TM. Image US /Maxar Technologies. Geologycal Survey.

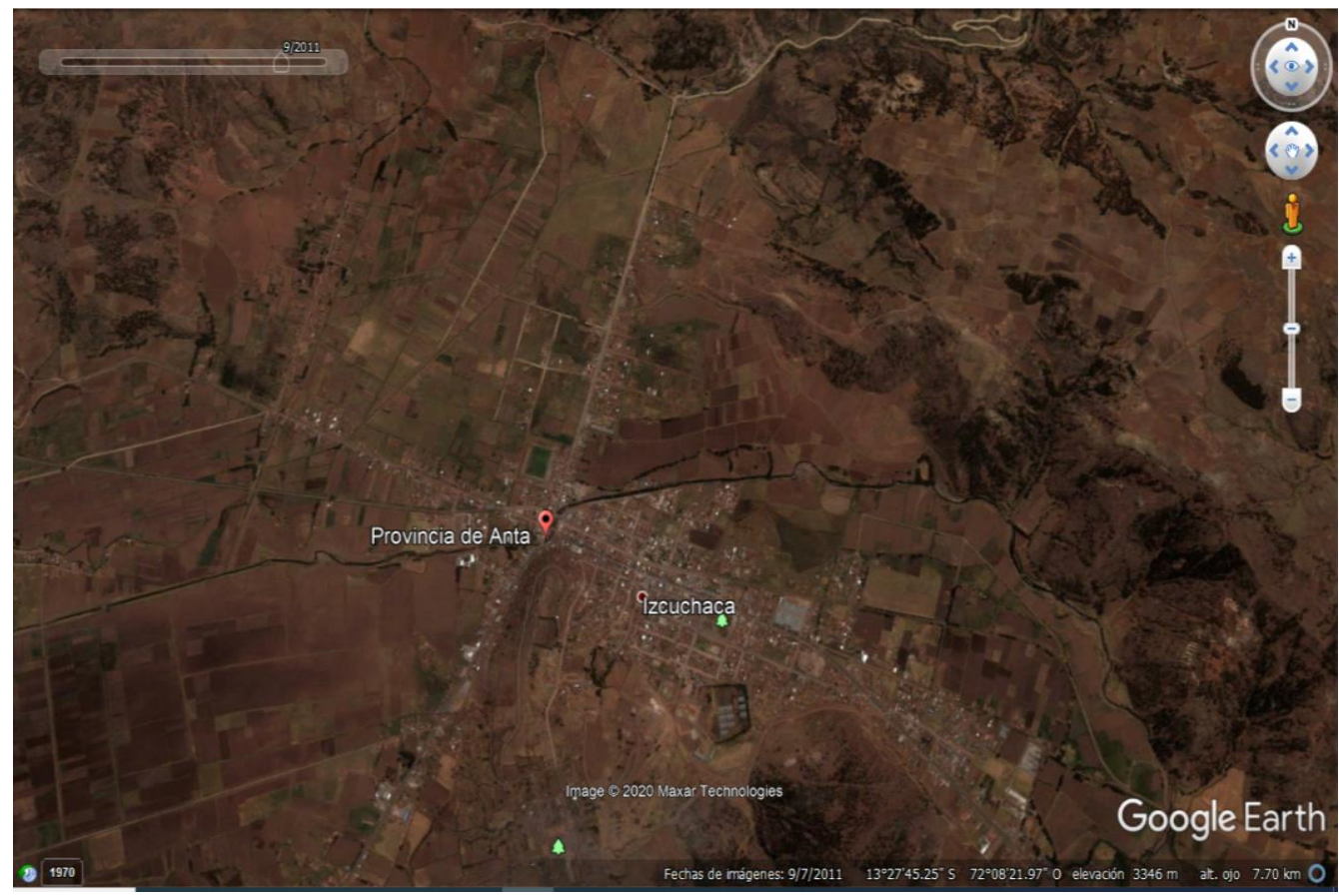

Captura fotográfica. Provincia de Anta, región Cusco. Territorios comunales San Cristobal de Llucanay y otras, avance zona urbana. Imagen 09.07.2011. Fuente: Apple TM + Google TM. Image US /Maxar Technologies.

Ciencia Latina Revista Científica Multidisciplinar, Ciudad de México, México.

ISSN 2707-2207 / ISSN 2707-2215 (en línea), julio-diciembre, 2020, Volumen 4, Número 2.

https://doi.org/10.37811/cl rcm.v4i2.90 p. 445 


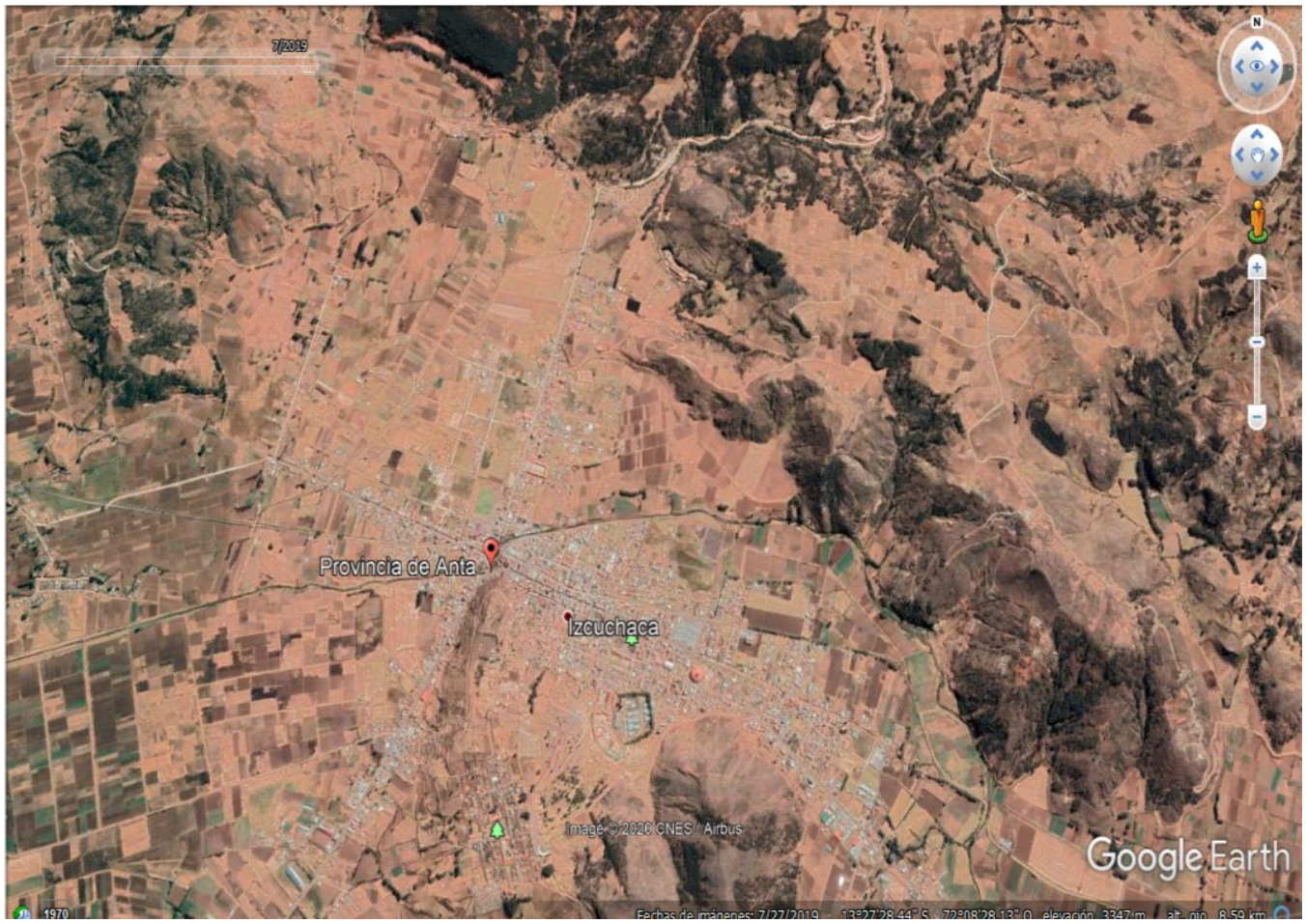

Captura fotográfica. Provincia de Anta, región Cusco. Ex territorios comunales San Cristobal de Llucanay y otras, ahora zona urbana. Imagen 27.07.2019. Fuente: Apple TM + Google TM. Image US/CNES /Airbus.

\section{DISCUSIÓN}

Según Hernández et. al (2017) las transformaciones que ocurren en las propiedades edafológicas, por el cambio de uso de los suelos, en los diferentes ecosistemas; en la investigación se presentan los resultados sobre cambios en sus características morfológicas que son apremiantes, además que sustentan la pérdida de biodiversidad y soporte del ecosistema, ello producto de la actividad antropogénica, como: sobrepastoreo que degrada el suelo, prácticas de manejo de cultivo inorgánicas, esto genera como consecuencia el abandono de las tierras, hacia otras o ciudad para buscar mejorar los ingresos. Para el caso de los distritos de Andahuaylas y Anta, la actividad antropogénica se centró en el abandono de tierras, la proximidad a la ciudad principal, el minifundio sobre el minifundio que consolidó el proceso de conversión del uso del suelo, que afectó la dinámica del paisaje natural, cultural, afectó obturando o desapareciendo las vías hídricas de defogue ante prevención de inundaciones, pérdida de servidumbre ante apropiación u ampliación de linderos de la propiedad. Asimismo, Velásquez \& Bocco \& Siebe (2014) demuestran que el de suelo es una expresión cultural de las prácticas de apropiación del territorio, cuya escala de análisis es a nivel de parcelas, que contienen patrones que nacen de acciones consensuadas por los actores sociales, el cambio de uso del suelo, es la forma permanente práctica de apropiación del territorio. Para el caso de los distritos de Andahuaylas y Anta, las prácticas de apropiación también son consensuadas a nivel familiar y comunal, sostenido en la atomización sobre la atomización, cuyo pilar es el crecimiento familiar, es decir incremento de miembros de 
la familia, esta atomización permitió llegar a heredar la posesión del padre, dividiendo el predio cercano a la ciudad en pequeñas parcelas donde se construye viviendas, iniciando el proceso de habilitación urbana, cuya expansión fortalece para crear un Centro Poblado Menor.

Valle y Huamán (2019) el suelo destinado a la agricultura, adquiere un valor representativo en el tiempo a partir de un aprovechamiento racional que generalmente es a mediano plazo, y los retornos de la inversión son considerables, si se realiza en suelos de superficie grandes conocidos como fundo o hacienda. La agricultura basada en el aprovechamiento racional de superficies pequeñas conocidas como minifundio, sus retornos de inversión muchas veces son ínfimos o negativos. El cambio de uso de suelo, el mercado de tierras, son acciones, actividades de las personas o grupos que realizan sobre un determinado tipo de superficie, revirtiendo la primera forma de explotación hacia una nueva. Para el caso de los distritos de Andahuaylas y Anta, la propagación del sistema de minifundio como forma de vínculación, red social, generó las condiciones para fortalecer el cambio de uso de suelo, aprovechar la demanda de suelo urbano para vivienda, que asegura un beneficio para el propietario o posesionario del predio, contenido en la habilitación urbana. Asimismo, el mercado de tierras, la dinámica de las transacciones en la zona urbana, permite que el predio semi o no agrícola, habilitado para sanemaiento básico, tome mayor valor, que es producto de la titulación de tierras, desde este punto el mercado de tierras siemrpe se mantuvo incipiente, poco organizado. Acompaña las argumentaciones sobre la conversión de uso del suelo y de los territorios comunales, Romero (2016) cuando determina para el caso de la ciudad de Lima, que los territorios de las comunidades campesinas se concentran al sur y este, entre los distritos de Comas, Carabayllo e Independencia, son próximas a la capital Lima; se permitió tomar parte del territorio para ampliación de carreteras primarias y secundarias, proceso sucede por el motivo de la legislación vigente, donde se aprueba competencias para los gobiernos locales y el Ministerio de Vivienda. La formación de dirigencias paralelas, ajenos a la comunidad, que invaden y luego buscan contacto para legitimar su posesión, la cual se fortalece cuando se ejecuta una obra pública, siempre y cuando el terreno sea de libre disponibilidad. En la comunidad se invade una porción de territorio, se asientan, dando la figura de asentamiento humano, e inician el proceso de legitimar su posición, mediante la fuerza o reivindicación de la comunidad u otros. Para el caso de los distritos Andahuaylas y Anta, se confirma la intervención de dirigencias paralelas, pero no como invasión, sino como proceso de conversión del uso de suelo consentido por la comunidad campesina, cuando las parcelas producto de la atomización, están próximos a la zona de expansión urbana, generan condiciones propias entre los dirigentes y dirigidos, consolidan una red fortaleciendo el proceso de habilitación urbana.

Además, Cuadros (2019) la comunidad campesina de Orcotuna, ubicada en al valle del Mantaro, proviene de un origen colonial, reconocida la organización comunal y titularidad del territorio comunal. No nace con la reforma agraria, por ello los cambios en la tenencia de la tierra y el uso de la misma son influenciados por los procesos administrativos de titulación de tierras ejecutados 20 años atrás, los cuales generaron tensiones. Los procesos de titulación de tierras, mediante la modalidad administrativa contribuyó a que áreas eriazas o en supuesto abandono al interior del territorio comunal fueran posesionadas, iniciando un proceso de expansión urbana, mediante las constancias de posesión u otros documentos que avalan la posesión o conducción del terreno o predio. 
Para el caso de los distritos de Andahuaylas y Anta, es lo contrario las comunidades campesinas con presencia de procesos de conversión de cambio de uso del suelo, fueron creadas por Reforma Agraria, entonces, tienen poca cultura desarrolla ancestral, los vínculos nacen desde relaciones de parentesco y mercantiles, limitando la reciprocidad y el sentido de comunidad campesina, e inclusive mantienen prácticas de compra-venta a pesar de estar prohibido.

Valle y Cruz y Yauris (2020) la conclusión respecto “A mayor generación de riqueza a partir de una adecuada organización comunal al interior del territorio comunal, mayor será la acumulación de capital en la ciudad". Para el caso de los distritos de Andahuaylas y Anta, se desarrolla y comprueba cuando la comunidad campesina, permite, consiente, la repartición del predio del padre a sus hijos, y estos a sus hijos, lo cual rompe la superficie agrícola adecuada para producir, construyen vivienda e inician el proceso de habilitación urbana, la titulación del predio obtenido a partir del minifundio sobre el minifundio, y la habilitación urbana es la que genera mayor valor y ello se transforma en riqueza y capital, porque sirve para conseguir otros bienes.

\section{CONCLUSIÓN}

Basado en la experiencia de las ex autoridades comunales, datos de georreferenciación, capturas satelitales, leyes de formalización de la propiedad rural, que el cambio de uso del suelo agrícola hacia suelo urbano, se centró en: el valor que adquirió el predio rural cuando se formaliza con un título de propiedad esto para los predios de particulares o dominio privado, la proximidad de los territorios comunales campesinos, cuyas formas organizativas cambiaron con el tiempo, estableciendo una disfunción organizacional y esta, abriendo camino a la división y partición de predios agrícolas, sumado al papel de la autoridad representativa del poder judicial, el juez de paz, que sirvió para consolidar proceso de transferencia internos de predios rurales próximos a la zona urbana. A pesar que la ley 24656, es tácita, respecto al proceso de compra venta al interior de la comunidad campesina y teniendo vigente la constitución política del Perú del año 1993, donde indica que la pérdida de la condición de comunidad y parcelación ocasiona el re vertimiento de tierras hacia el estado; ello no es suficiente porque las formas asociativas y condiciones de posesión en tierras eriazas comunales, de los asentamiento urbano marginales, presentan otra connotación, creando un nuevo contexto de necesidad poblacional y atención del estado. 


\section{LISTA DE REFERENCIAS}

Arias, F. (2012). El Proyecto de investigación (sexta ed.). Caracas: Episteme.

Bernal, C. (2010). MetodologÍa de la Investigación (tercera ed.). Colombia: Pearson.

Bocco, G. (2007). "Reflexiones sobre Geografía, Ambiente y Geografía Ambiental". Presentación visual de la ponencia ofrecida en la Cátedra de Geografía Humana Elisée Reclus. México.

Carrasco, \& Sergio. (2008). Metodología de la Investigacion Cientifica. Perú: San Marcos.

Carrasco, S. (2005). Metodología de investigción científica (Primera ed.). Lima: San Marcos.

Clout, H. D. (1976). “Geografía rural. Elementos de geografia”. Oikos - Tau, S.A. ediciones. España.

Cuadros, Hans. (2019) Cambios en la tenencia y el uso de la tierra en comunidades campesinas, en el contexto de procesos de urbanización y saneamiento rural: el caso de la comunidad campesina de Orcotuna. Pontifica Universidad Católica del Perú.

El Peruano (1969) Ley 17716. Ley general de Reforma Agraria del Perú. Separata de normas legales. Jun.

El Peruano (1987) Ley 24656. Ley general de comunidades campesinas y nativas del Perú. Separatas de normas legales. Abr.

El Peruano (1987) Ley 24657. Ley del deslinde i titulación de comunidades campesina y nativas del Perú. Separata de normas legales. Abr.

Hernández, R., Fernández, C., \& Baptista, P. (2014). Metodologia de la Investigación. Mexico: Mc Graw-Hill.

Hernández Jiménez, Alberto, Vera Macías, Leonardo, Naveda Basurto, Carlos Alfredo, Guzmán Cedeño, Ángel Monserrate, Vivar Arrieta, Marco, Roberto Zambrano, Teódulo, Mesías Gallo, Freddy, Ormanza, Katty, León Aguilar, Rolando Venancio, \& López Alava, Geoconda Aracely. (2017). Variaciones en algunas propiedades del suelo por el cambio de uso de la tierra, en las partes media y baja de la microcuenca Membrillo, Manabí, Ecuador. Cultivos Tropicales, 38(1), 50-56.

Instituto Nacional de Estadística e Informática (2018) Cifras e indicadores de pobreza monetaria. Sección Apurímac. INEI. Lima-Perú. 
Juan Pérez, José I. (2013) ANÁlISIS DEL CAMBIO DE USO DEL SUELO EN UNA REGIÓN DEL ALTIPLANO MEXICANO. RETOS E IMPACTOS: 1986 - 2011. Revista OIDLES - Vol 7, No 13 (2013). ISSN: 1988-2483.

Ministerio de Agricultura. (1999) Directorio de comunidades campesinas del Perú. Proyecto Especial de Titulación de Tierras y Catastro Rural. Editorial R \& R publicistas asociados. Lima - Perú. 1 edición.

Ministerio de Economía y Finanzas del Perú (2020) Cifras e indicadores macroeconómicos del Perú. Sección Estadísticas regionales. MEF. Lima-Perú.

Romero, Erick (2016) Expansión urbana y comunidades campesinas. DESCO. Revista Que hacer. Hora Cero.

Valle, Felipe \& Huamán, Yersi. (2019) Proceso de titulación en la zona de producción agrícola del margen izquierdo río chumbao, Andahuaylas, Perú, años 2004 al 2017. International Journal of Innovation and Scientific Research ISSN 23518014 Vol. 42 No. 1 Apr. 2019, pp. 33-39.

Valle, Felipe \& Cruz, Adalberto \& Yauris, William. (2020) La riqueza en los territorios comunales campesinos y su relación con la acumulación de capital inmueble en las ciudades de Andahuaylas y Chincheros, región Apurímac, Perú. Revista Estudios del Desarrollo Social: Cuba y América Latina. ISSN 2308-0132 Vol. 8 No. 2, agosto 2020, pp. 129-140.

Velásquez, Alejandro \& Bocco, Gerardo \& Siebe, Christina (2014) Cambio de uso de suelo. Red temática de CONACYT sobre Medio Ambiente y Sustentabilidad. Compilada por M. Maass y M. Equihua. 